\title{
La importancia de una cultura exportadora en el territorio del departamento de Nariño
}

\author{
Diego Germán Martínez Delgado ${ }^{1}$ \\ Alicia Cristina Silva C. ${ }^{2}$ \\ Julio Cesar Montoya $\mathrm{R}^{3}$.
}

\section{Resumen}

Las necesidades cambiantes y crecientes, así como la exigencia de nuevos y mejores productos han llevado a las sociedades a buscar otros productos para llevar sus mercados y nuevos mercados para ofrecer su producción, como consecuencia de esto hoy se vive bajo parámetros económicos globales, con políticas económicas orientadas a favorecer la competitividad y afianzar sus productos en mercados internacionales.

La competitividad que exigen estos mercados es muy alta, y la preparación es uno de los ejes trasversales para afianzarse en la economía internacional, de igual manera el desarrollo de una cultura empresarial exportadora, pero apuntando a nuevas posibilidades económicas como es la agroindustria, el mercado exige productos con mayor valor agregado y mejores niveles de transformación, tanto en el suministro de materias primas o en alimentos, también en recursos naturales, cultura, turismo, etc.

Sin embargo, a pesar de conocer esta realidad, el Departamento de Nariño, no ha sido capaz de implementar un plan verdaderamente exportador, pues son varios los

\footnotetext{
${ }^{1}$ Economista, Especialista en Proyectos de Desarrollo, Magister en Mercadeo Agroindustrial. Docente ocasional UNAD. Grupo de investigación Sindamanoy

${ }^{2}$ Administradora de empresas, especialista en Pedagogía para el Desarrollo del Aprendizaje Autónomo. Magíster en Sistemas de Calidad y Productividad.Estudiante de Doctorado de Administración de Negocios, mención Gerencia. Docente Universidad Nacional Abierta y Distancia - UNAD. alicia.silva@unad.edu.co

${ }^{3}$ Administrador de Empresas, Especialista en Pedagogía para el Desarrollo del Aprendizaje Autónomo, Maestría en Administración de Empresas.Docente de la Universidad Nacional Abierta y a Distancia - UNAD. julio.montoya@unad.edu.co
} 
obstáculos que ha enfrentado y se han convertido en barreras que históricamente han desfavorecido el desarrollo.

La necesidad de favorecer en el departamento de Nariño una real cultura exportadora es innegable, bajo unos parámetros claros, dinámicos y auspiciadores del empresarismo regional.

Palabras claves

Cultura exportadora, Competitividad, Alternativas de desarrollo, Potencialidades

\section{Introducción}

La historia nos muestra que el comercio internacional se ha abierto camino para llegar a todas las sociedades, generando diferentes impactos y transformaciones, dependiendo de la velocidad con que llega y de la capacidad que tengan los miembros de esa sociedad para absorberlo. Desde antes del siglo XXI se habla de grandes procesos de globalización, transmitiendo un mensaje en el que todas las personas son un solo mundo, en el que todos tienen acceso a mejores condiciones económicas, a educación y mejor calidad de vida.

Pero esto no es gratis, hay que prepararse, no es solo el libre movimiento de capitales o de inversiones, está además la calidad de vida del ser humano; hoy por hoy, si se quiere crecimiento y desarrollo económico y social es indiscutible la obligatoriedad de incluirse en el proceso de globalización de la economía, asumiendo compromisos de cambio como mejoramiento en infraestructura, y sobre todo, generando y cultivando una cultura empresarial exportadora. La oportunidad de alternativas que antes no eran consideradas suficientes como es la agroindustria rural, se requieren diseñar y organizar en su verdadera 
dimensión, como lo expone Pérez (200, un proceso de mejora del nivel del bienestar de la población rural y de la contribución que el medio rural hace de forma más general al bienestar de la población en su conjunto, ya sea urbana o rural, con su base de recursos naturales.

\section{Desarrollo del documento}

Cabe anotar que, lo rural o mejor la empresa agroindustrial rural sobrepasa lo meramente agropecuario e inicia vínculos comerciales e industriales con la ciudad, tanto en la provisión de alimentos como en otro tipo de bienes y servicios como la oferta de recursos naturales, turismo, cultura, etc. ${ }^{4}$

Frente a este aspecto, el Departamento de Nariño ha encontrado un sin fin de obstáculos que han impedido su normal desarrollo económico, tales como: su posición geográfica distante del centro del país y de sus polos de desarrollo, la inadecuada infraestructura vial y de comunicaciones, siempre mirando el comercio interno, sin dirigir sus recursos hacia el comercio internacional con el Ecuador y el sur del continente. El temor de enfrentar nuevos mercados y la falta de credibilidad en la capacidad del nariñense no le ha permitido salir de esa zona de falso confort, en donde se ha mantenido, pero no ha

\footnotetext{
${ }^{4}$ Al respecto, CLACSO (2001), en el libro Desarrollo Rural ¿Una nueva ruralidad en América Latina?, Dice: "Bajo esta concepción de progreso económico, la transformación estructural va de lo rural hacia lo urbano, de lo agrícola a lo industrial, y por ende de lo atrasado a lo moderno"

Según este planteamiento, lo rural se ajusta pasivamente y en función de factores exógenos. En el plano productivo el comportamiento agrícola es residual, y depende de las demandas industriales y urbanas. Lo endógeno en el sistema es la urbanización y la industrialización; y el resultado, la modernización tanto en términos técnicos como en el sistema de ideas y valores. (página 18)
} 
avanzado con la velocidad que requieren hoy los mercados internacionales. La separación del sector rural del urbano es una concepción que no debe mantenerse; es necesario definir un horizonte de desarrollo y de cambio integral eliminando la línea imaginaria que separa lo rural de lo urbano para iniciar procesos dinámicos y sostenidos de manera conjunta de tal manera que la agroindustria rural crezca y se convierta en un eje clave en el desarrollo económico exportador.

Es importante entonces asumir e instrumentar una cultura exportadora en este territorio con todo lo que ello implica: nuevas formas y expresiones, costumbres, prácticas, normas, reglas y comportamientos, capacidad para obtener información y habilidades para utilizarla en su propio beneficio y del territorio.

Un punto positivo se encuentra al revisar el plan regional de competitividad (2009) del departamento de Nariño; entre sus metas está el mejoramiento del bienestar de la población tomando a las exportaciones como como uno de los ejes centrales por su capacidad de convertirse en el motor del crecimiento económico y de la generación de empleo a mediano y largo plazo.

Esta meta es en sí misma muy buena, el departamento de Nariño puede mejorar su competitividad, y ser más productivo, valorando sus potencialidades humanas, naturales, geográficas, etc. que se facilite el proceso para incorporarse de manera dinámica en la globalización y apuntalándose en la creación de una estructura productiva exportadora sólida, que surja como uno de los elementos que jalone a la economía nariñense y se refleje como beneficio socio económico. 
Esto implica el diseño de estrategias que le permitan identificar y aprovechar sus potencialidades o ventajas competitivas, desarrollar sus cadenas productivas, generar alianzas estratégicas, forjar sinergias que le permitan salvar los obstáculos y aprovechar sus fortalezas y las oportunidades que el mercado internacional le brinda, diversificar sus productos y ampliar sus mercados, aprovechando para esto los acuerdos y tratados que Colombia ha firmado.

En la siguiente tabla se pueden observar las exportaciones nariñenses por productos, estos pocos productos a julio de 2011 representan el $96.5 \%$ del total de las exportaciones, este valor por si solo muestra que no tenemos unas exportaciones diversificadas, Nariño está en demora de buscar nuevos mercados para sus productos y nuevos productos para los mercados.

\author{
Departamento de Nariño \\ Principales productos de exportación (2009 - 2011)7 \\ Miles de dólares FOB
}




\begin{tabular}{|c|c|c|c|c|c|}
\hline \multirow{2}{*}{ Partida } & \multirow{2}{*}{ Descripción * } & \multicolumn{2}{|c|}{ Enero-Diciembre } & \multicolumn{2}{|c|}{ enero - julio } \\
\hline & & 2009 & 2010 & 2010 & 2011 \\
\hline 0901 & Café, incluso tostado o descafeinado, cáscara y cascarilla de café; such & 38.077 & 45.876 & 15.704 & 41.551 \\
\hline 1511 & Aceite de palma y sus tracciones, incluso refinado, pero sin modificar qu. & 6.631 & 2.512 & 796 & 3.056 \\
\hline 4202 & Baíles, maletas (valjas), maletines, incluidas los de aseo y los portado & 298 & 625 & 331 & 471 \\
\hline 3402 & Agentes de supericie orgánicos (excepto el jabón), preparaciones tenso & 35,286 & 86 & 35 & 324 \\
\hline 3608 & Insecticidas, raticidas y demás antirnoedores, fungicidas, herbicidas, int & 27 & 52 & - & 168 \\
\hline 3926 & Las demás manufacturas de plástico y manufacturas de las demás mat & 31 & 10 & 9 & 147 \\
\hline 3304 & Preparaciones de belleza, maqu' laje y para el cuidado de la piel, excep & 36 & 19 & 17 & 140 \\
\hline 0713 & Hortalizas de vaina secas desvainadas, aunque estén mondadas o parti. & - & 695 & - & 133 \\
\hline 3307 & Preparaciones para afeitar o para antes o después del afeitado, desodor & - & 15 & 7 & 118 \\
\hline 4902 & Diarios y publicaciones periódicas, impresos, incluso ilustrados o con p & 128 & 120 & 93 & 108 \\
\hline 3105 & Abonos minerales o químicos, con dos o tres de los elementos fertilizar & - & - & - & 96 \\
\hline 6403 & Calzado con suela de caucho, plástico, cuero natural o regenerado y pa & 1 & 3 & 3 & 90 \\
\hline 8540 & Lámparas, tuloos y válulas electrónicos, de cátodo caliente, cátodo fío & - & - & - & 89 \\
\hline 9603 & Escobas y escobilas, cepilas, brochas y pinceles (incluso si son parte & - & 50 & 20 & 71 \\
\hline 9018 & Instrumentos y aparatos de medicina, cingia, odontología o veterinaria, & 11 & 23 & 11 & 65 \\
\hline \multicolumn{2}{|c|}{ Subtotal principales productos } & 45.275 & 50.085 & 17.024 & 46.625 \\
\hline \multicolumn{2}{|c|}{ Participación \% } & 81,3 & 94,5 & 89,7 & 96,5 \\
\hline \multicolumn{2}{|c|}{ Total departamento } & 55.690 & 53.023 & 18.971 & 48.300 \\
\hline
\end{tabular}

Fuente: Ministerio de Trabajo (2011)

Es aquí donde surge la necesidad de crear en el territorio del departamento de Nariño una real cultura exportadora, seguir los lineamientos de la agenda exportadora y del plan departamental de competitividad, y a la vez concienciar a los empresarios, a los emprendedores, a los estudiantes, que las oportunidades de negocios que ofrece el mercado internacional les mejorará las condiciones de vida y que a su vez le permitirá fortalecer el mejoramiento de la competitividad de su territorio.

Es claro que la cultura exportadora no surge de la inmediatez, pero si puede ser el resultado de un conjunto de estrategias y esfuerzas del sector público y privado encaminados hacia el mejoramiento de la competitividad empresarial y el mejoramiento de la calidad de vida de la población. Ahora bien, tal como lo definen diferentes autores, se puede decir que la cultura exportadora es el conjunto de capacidades generales que tiene 
una población para llegar al mercado mundial y para comercializar la producción nacional en los mercados internacionales, por lo tanto una de las estrategias está en la educación, brindándoles a los estudiantes las herramientas para conocer cómo funciona el comercio internacional, y de qué forma con los recursos que tiene el departamento pueden ingresar a este espacio de manera competitiva. En un estudio realizado por CEPAL y UNESCO (1996): Educación y conocimiento: eje de la transformación productiva con equidad, se presenta la necesidad de un acceso global a los nuevos conocimientos, entendidos como el "conjunto de conocimientos y destrezas necesarios para participar en la vida pública y desenvolverse productivamente en la sociedad moderna". Aunque este concepto es aplicado a capacidades generales en la infancia -manejo de las operaciones aritméticas básicas, la lectura y comprensión de textos, la comunicación escrita, etc.-, puede hacerse extensivo en este caso a la cultura exportadora, en cuanto la enseñanza de ésta en la educación superior permite adquirir a los estudiantes capacidades generales para insertarse en el mercado global

El departamento de Nariño requiere de un conjunto de estrategias que le ayude al surgimiento de una cultura exportadora, por eso es necesario iniciar un proceso participativo, convocando empresarios, universidades, instituciones, alrededor del diseño y elaboración de una planificación con conciencia y compromiso por un territorio capaz de salir adelante y mantenerse y crecer en este proceso.

Es fundamental que este proceso se desarrolle en torno al fomento de las exportaciones y apoyado en aspectos de formación e integración de la comunidad (Ortiz, 1999) no se puede pensar en desarrollo y crecimiento económico si se continúa trabajando con su mercado 
natural y con los productos que la tradición han dejado; es necesario salir y buscar nuevos mercados, conocer necesidades de otros pueblos y ofrecerles soluciones con productos de calidad, desarrollar vocación exportadora, que le permitan alcanzar objetivos como los siguientes:

1. Presentar un portafolio diversificado en productos y mercados

2. Participar de alianzas estratégicas con las empresas de la región y de los mercados de destino

3. Aprovechar los tratados y convenios firmados por Colombia

Pero para alcanzar estos objetivos se deben tener en cuenta unos aspectos indispensables como son:

1. Las fuerzas vivas del departamento deben liderar el proceso, mantenerlo y hacerlo crecer.

2. Adquirir compromiso y dinamismo entre el sector público y privado (empresas industriales, comerciales y agrícolas, cámara de comercio de pasto, Ipiales y Tumaco, universidades, etc.).

3. Creación del equipo de trabajo del plan de competitividad. Con carácter y optimismo por el departamento de Nariño.

4. Apoyo de las alcaldías y gobernación al proceso.

5. Integración y formación de la comunidad.

El punto inicial para la formación de una cultura exportadora es conocer la situación actual a través del reconocimiento y autoevaluación de la capacidad empresarial, de la potencial oferta exportadora, del nivel de competitividad de departamento y su grado de 
aprovechamiento y su inserción en el comercio internacional. Un segundo punto, es fijar un horizonte, definir unos escenarios prospectivos e identificar de ellos cual es el óptimo de acuerdo con la disponibilidad de recursos y las metas a alcanzar, para según esto, definir la visión exportadora del departamento.

Como tercer punto, es indispensable la definición de objetivos, que apunten a lograr un entorno competitivo que genere certidumbre y confianza para el desarrollo de las actividades productivas. Con estos objetivos se debe iniciar el surgimiento de una cultura exportadora, la creación de empresas, el desarrollo de la infraestructura, financiamiento, en general el desarrollo del territorio.

Un cuarto paso, el departamento de Nariño tiene identificadas unas cadenas productivas, sobre las que se ha trabajado y destinado recursos, como son las cadenas del cacao, café, coco, cuy, hortofrutícola, láctea, palma de aceite, panela, papa. Pesca y fique entre otras apuestas productivas de Nariño, es necesario entonces, continuar con estas cadenas para consolidar y aprovechar los resultados logrados. (PEDCTI Nariño, 2010)

Por último, el diseño de un plan de acción, como brújula que guíe y unifique los esfuerzos de los involucrados en este proceso, acompañados de un plan evaluador o un conjunto de indicadores de gestión que informen sobre los avances o retrocesos en el cumplimento de los objetivos, para avanzar o tomar medidas correctivas.

La estructura para el surgimiento de un adecuado proceso de cultura exportadora en el Departamento de Nariño aún no existe. Está equivocado el concepto en el que solo el incremento de las exportaciones es el reflejo del surgimiento de una cultura exportadora, es necesario trabajar sobre otras áreas que conduzcan no solo a transacciones comerciales sino 
también a la creación de vínculos y relaciones con mercados en el exterior, con posibles socios, etc.

Según Ramírez (1999) en "La Educación Como Instrumento de Fomento de la Cultura Exportadora" las relaciones internacionales no son solo transacciones comerciales es todo el territorio, en donde la comunidad debe estar involucrada en el proceso de integración y de formación. Por ejemplo, en colegios y universidades se debe iniciar a fortalecer el uso de las TIC, el manejo de un segundo idioma, talleres de manejo empresarial o gerencial, desarrollo agroindustrial, manejo del lenguaje comercial exportador, planes de negocios, planes exportadores, etc., Si las personas aprenden a convivir con estos conceptos y los hacen parte de su lenguaje se puede decir que se ha iniciado un proceso de cultura exportadora. Una persona que nace en el campo y se cría como agricultor, seguramente será un gran agricultor y su cultura será agrícola, así mismo si el entorno favorece el desarrollo de la cultura exportadora, seguramente, muchas personas se desarrollaran como tal.

\section{Referencias}

CEPAL - UNESCO. (1996). La producción del conocimeinto y el desarrollo. En C. UNESCO, Educación y conocimiento: eje de la transformación productiva con equidad (págs. 45-55). Lima (Peru): Tarea.

CLACSO. (2001). Hacia una nueva visión de lo rura. En E. Pérez, Una nueva ruralidad en América Latina? (págs. 17-29). Buenos Aires: CLACSO, Consejo Latinoamericano 
de Ciencias Sociales. Recuperado de

http://bibliotecavirtual.clacso.org.ar/clacso/gt/20100929011414/2perez.pdf

Comisión regional de competitividad. (2009). Plan regional de competitividad de Nariño.

Pasto. Recuperado de

http://www.mincit.gov.co/loader.php?IServicio=Documentos\&lFuncion=verPdf\&id

$=61291 \&$ name $=$ Narino_InformeFinal_PRC.pdf $\&$ prefijo=file

Ministerio del Trabajo. (2011). Programa nacional de asistencia técnica para el fortalecimineto de las politicas de empleo, emprendimento y generación de ingresos en el ambito regional y local. Bogotá.

Ortiz, R.E. (1999). Globalización una perspectiva desde el comercio y el desarrollo. Colombia Internacional, 54-71.

PEDCTI Nariño. (2010). Plan estrategico en CT+I de Nariño. Pasto, Colombia.

Ramirez, R.M. (1999). La educación como instrumento de fomento de la cultura exportadora. Colombia Internacional, 7-15. 